\title{
Instructional Videos for Seniors over 75: The Effects of Addressing Potential Errors in User Instructions
}

\author{
Marianne Scheepens \\ Mans57 \\ mail@mans57.nl
}

\author{
Joyce Karreman \\ University of Twente \\ j.karreman@utwente.nl
}

\author{
Menno de Jong \\ University of Twente \\ m.d.t.dejong@utwente.nl
}

\begin{abstract}
Using a laptop or tablet computer can be challenging for senior users, but using these devices can facilitate communication with family and care-givers. The goal of the current study is to get more insight in how to instruct and train senior users to use the keyboard of a tablet computer that is specifically designed for seniors (Compaan). Research has suggested that addressing errors and showing how to correct these errors can have positive effects on the learning process. Two series of video instructions were developed. In the first series, it was explained how to use the tablet computer without addressing potential errors. In the second series, potential errors were addressed. Forty seniors (75 - 97 years of age) participated in this study. The participants were asked to familiarize themselves with the Compaan, with the help of one of the series of instructional videos. Their learning progress, task effectiveness, and their self-efficacy and satisfaction levels were measured. The results showed that most participants were interested and motivated to learn to use the tablet computer. Participants who watched the videos in which potential errors were addressed performed somewhat better than the other group.
\end{abstract}

Index Terms - Error recognition, instructional videos, technology for seniors, usability

\section{INTRODUCTION}

\section{Low technology adoption of seniors}

Computers can be very helpful for the fast-growing group of seniors over 75 years of ages, for example to be informed, to communicate with family and care-givers or to combat social isolation [1], [2]. However, many seniors still have problems using computers [3], [4]. This is not surprising, because the group of seniors over 75 has not grown up with computer technology in a currently common way [5]. Computer technology for personal communication and entertainment was not available before around 2000. Men and women who are now older than 75 years of age stopped working for an income at least 10 to 15 years ago.

As society is digitalizing very fast and communication networks are changing, it is important to commit more effort towards designing technologies that can be understood by senior people and towards instructing and training them to use these technologies. However, considers designing technologies or user support for the group of seniors over 75 as important. It is sometimes assumed that seniors are not interested in technologies or that they lack the capabilities to use them. It is also assumed that future generations will not experience these problems anymore, because they have grown up using technologies. Therefore, these problems will solve themselves over time. However, technology is progressing fast. What is new today, is often obsolete in one or two decades [6], [7]. In contrast to common opinions mentioned above, seniors regard computers as useful and necessary in society, but they cannot see the usefulness for themselves, because of the lack of perceived (and real) usability [8]. Interface-designs that do not fit the capabilities (too many choices, information and/or navigational levels) of senior people, create negative experiences and lower motivation and selfefficacy. This can explain lack of interest or motivation, but - on the other side - once seniors join the online world, digital technology often becomes an integral part of their daily lives [3], [9].

To increase the adoption of technologies by seniors, these technologies need to be designed according to seniors' needs, wishes and capabilities. Moreover, this target group needs assistance in learning how to use the technologies [10]. 


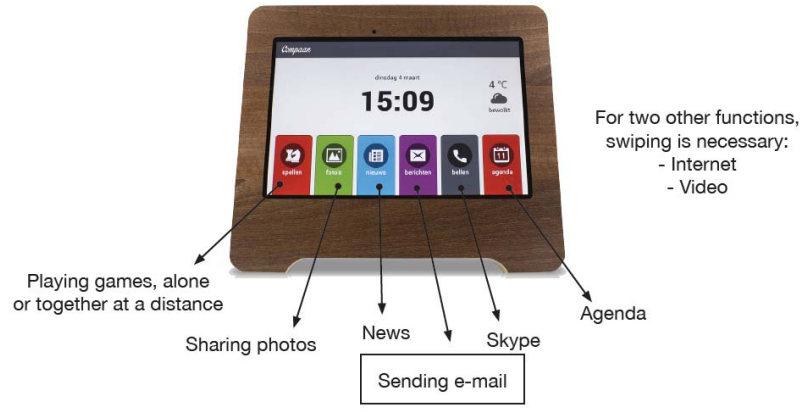

FIGURE 1. THE HOME SCREEN OF THE COMPAAN TABLET COMPUTER

\section{Compaan: a tablet computer for seniors}

Compaan is an adjusted tablet computer for senior users to communicate with family and friends, by sharing photos and videos, calling with Skype, sending messages and playing games. In addition, this tablet can be used to read the local newspaper, to watch church services, and to surf on the internet. By utilizing a simplified design, this tablet computer compensates for difficulties caused by cognitive declines, changes in sensory processes and movement control [11]. The guidelines for web accessibility are applied [12]. Distinct colours and contrast cues are used to support the elderly. Additionally, the screens are designed with 'clean' lines and distinct objects, and there are no complex arrangements of shapes which may cause confusion.

Compaan tablet computers function as sociotechnical systems [13]. They are linked to the computer of a family member/caregiver. This person invites family and friends to communicate with the senior user. This person can also remotely set preferences or solve a problem with the tablet computer. The computer of this family member or caregiver and the senior's Compaan are linked to the Compaan helpdesk for support and software updates. The success of the implementation of the Compaan system is therefore a mutual responsibility of the senior user, the family member/caregiver and the helpdesk of Compaan Company.

Although the Compaan system is designed to fit seniors' abilities, it is known that Compaan-users experience difficulties, for example, because of a lack of basic computer skills such as swiping and scrolling [14]. Most users use only one or two functionalities of the Compaan, such as sharing photos/videos and games, or calling with Skype. In these cases, the senior users are connected by their family member or caregiver. The only functionality of the Compaan that can be used by the senior users themselves to initiate a social connection is email. This functionality is not often used by the current users of the Compaan, although it can be very useful.

\section{Instructional videos for seniors}

Senior people need active practicing and regular repeating to be able to develop computer skills [15], [16]. Trainings and instructions must consider these needs [17]. Integrating video-instructions or e-learning programs into technical devices seems a promising approach to close the knowledge gap of senior users. Bruder, Blessing and Wandke [18] developed a successful task oriented elearning program to teach mobile use to people between 50 and 77 years. Another study showed that videoinstructions were more beneficial than text based instructions for people of 60-75 years of age towards knowledge-acquisition in an interactive system [19].

Struve and Wandke [20] conducted a study in which they instructed seniors between 60 and 74 years of age on how to use a ticket vending machine. They designed two variants of video-instructions: the 'error-free' videoinstructions showed how to perform the right actions, whereas the 'error guided' instructions also showed frequently occurring problems and how so solve them. The participants in the 'error guided' group proved better results for decreasing the number of errors, and gained more structural knowledge. These results are in line with the Minimalist approach to designing instructional materials. The third minimalistic principle is: support error recognition and recovery [21]. However, including information on error recognition and recovery results in more extended instructional materials, which may have adverse effects on the training process of seniors because of their declining cognitive capabilities.

\section{Research goal}

The goal of this study was to compare the effects of 'error guided' instructional video materials with the effects of instructional video materials that did not include information on potential errors. The effects of the video materials on senior's learning progress, task effectiveness, and on their satisfaction and self-efficacy levels were measured.

\section{METHOD}

\section{Development of the instructional videos}

Two series of eight instructional videos were developed, using an iterative design procedure. Three rounds of (re)designing and usability testing resulted in the videos that were used in the study.

Both series of videos were designed using instructional methods to enhance learning and to reduce cognitive load. A list of design guidelines was formulated, based on previous studies:

- Instructions should consist of four main components: goal setting, prerequisites, preparing users for actions and reactions and warnings [22]; 
- Instructions should follow the mental model of the user in an action sequence, and be faithful to the actual interface [23];

- Motivational elements should be included in the instructional materials, because these elements are beneficial when seniors experience difficulties [24];

- The structure of the instructions should be clear [23];

- $\quad$ Familiarity should be created using the company style of Compaan (logo, colours, fonts) [25];

- The voice-over must slightly precede the video images [26];

- High quality audio and video is required [26];

- The videos should be as short as possible [23].

In the first series of videos (duration: 13 minutes), it was explained how to use the keyboard and how to type and send an e-mail message using the Compaan tablet without addressing any potential errors. The second series of videos (duration: 16 minutes) was the same as the first, but in each of the eight videos, one or two potential errors were addressed. One of the potential errors was related to accidentally deleting text: "What happens quite often is, that too many letters are deleted. That happens when the Del- or Back-key is pressed too long. Do not be scared, that happens to all of us. Unfortunately, you should tap the disappeared words again, because there is no button to restore at this moment."

\section{Participants}

Family members of new Compaan-users over 75 years of age or older with no or very little computer-experience were asked by phone if they thought their relative would like to participate in this research. If so, they received a letter with the intention of the study and the senior users were asked personally by phone. Forty new Compaanusers of 75 to 97 years old $(\mathrm{M}=83.93, \mathrm{SD}=5.17)$ participated, 34 women (85\%) and six men (15\%).

The participants' jobs before retirement varied. Nineteen of them were housewives for the longest part of their lives (four of them educated as teachers when they were young), 11 persons owned a company with their partner (shoe shop, farm, garden centre), three worked as carpenters, two performed administrative work, two worked as typists, two were production employees, two persons were employed in a managerial function and one participant assisted her husband, who was a GP. The majority of the participants received the Compaan no longer than a month ago. Some of them received the Compaan a bit longer ago, but no longer than eight months ago. Nineteen participants had no computerexperience at all. Twenty-one participants had a little bit experience but chose to use a Compaan, because an IPad or a comparable device was too difficult to use for them.
Participants were randomly assigned to one of the two groups. There were no significant differences in age between the groups. The mean age of the participants in the 'error free' group was 83.95 years old $(\mathrm{sd}=4.76)$ and the mean age of the participants in the "error guided" group was 83.90 years old $(\mathrm{sd}=5.67)$.

\section{Study procedure and measurements}

The Compaan-users participated in the study in their own environment. A researcher (the first author of this paper) visited them at home. This was done to increase the ecological validity of the study: the learning and testing context was similar to the situation in which the participants actually would have to use the tablet computer. The study was approved by the Ethics Committee of the faculty of Behavioural, Management and Social Sciences of the University of Twente in the Netherlands.

Each session started with a short introduction, the first video was shown to the participants. This video served as a general introduction. All key concepts were mentioned for the first time in this video.

After watching the first video, the participants answered questions that measured their knowledge on the actions related to sending e-mails. Two series of questions were asked. The first series consisted of questions about the participants' knowledge of the functions of several buttons on the screen. A screen capture was shown to them and they were asked to explain the function of eight different buttons (the space bar, the button for capitalizing letters, et cetera). The second series of questions measured the participants' ability to recall how they key board looked like. A series of six screen captures was shown to them. Each time, the inscription on one of the buttons was removed. The participants were asked if they could remember what icon, word, letter was on that button.

After finishing the knowledge test, the training phase started. The participants were asked to watch five short videos in which sub-tasks of the process of sending an email were explained and demonstrated. The participants had to practice this sub-task after every video. This training phase ended with watching a video in which the functionalities of the most important keys were repeated and a concluding video about how to send an e-mail.

After the training phase, the test phase started. The participants were asked to find a person in the contact list, to type a prescribed e-mail message and send it. To correctly imitate the prescribed message, the participants had to use many key board functions. The test was video recorded. Their task effectiveness was measured by observing the number of correctly performed sub-tasks, out of eight sub-tasks. Examples of these sub-tasks are: to use capital letters, to include a smiley face and to include an exclamation mark. 
After finishing the task of sending an e-mail message, the participants were asked to answer the same two series of questions as before the training phase, to measure their learning progress.

Two weeks later, the participants were called to ask about their satisfaction with the Compaan tablet and about their level of satisfaction and self-efficacy. This phone call was audio recorded.

\section{RESULTS}

\section{Learning progress}

The effectiveness of the learning process was measured by the knowledge test that the participants performed before and after watching the instructional videos. The knowledge test consisted of eight questions about the function of several buttons and of six questions about the participants' ability to recall the appearance of several buttons. See table 1 for the mean numbers of correctly answered questions.

TABLE 1. THE EFFECT OF THE TWO VERSIONS OF THE VIDEO INSTRUCTIONS ON LEARNING PROGRESS (MEAN SCORES AND STANDARD DEVIATIONS).

\begin{tabular}{|l|l|l|l|l|}
\hline & \multicolumn{2}{|l|}{$\begin{array}{l}\text { Video without } \\
\text { reference to } \\
\text { errors }\end{array}$} & \multicolumn{2}{l|}{$\begin{array}{l}\text { Video in which } \\
\text { errors were } \\
\text { addressed }\end{array}$} \\
& $\begin{array}{l}\text { Pre- } \\
\text { test }\end{array}$ & $\begin{array}{l}\text { Post- } \\
\text { test }\end{array}$ & Pre-test & $\begin{array}{l}\text { Post- } \\
\text { test }\end{array}$ \\
\hline $\begin{array}{l}\text { Explanation of } \\
\text { functions } \\
\text { (max. score: } 8)\end{array}$ & $\begin{array}{c}2.95 \\
(1.36)\end{array}$ & $\begin{array}{c}6.35 \\
(1.57)\end{array}$ & $\begin{array}{c}3.90 \\
(1.68)\end{array}$ & $\begin{array}{c}6.85 \\
(1.35)\end{array}$ \\
\hline $\begin{array}{l}\text { Recall buttons } \\
\text { (max. score: 6) }\end{array}$ & 2.90 & $\begin{array}{c}4.60 \\
(2.00)\end{array}$ & $\begin{array}{c}2.80 \\
(1.57)\end{array}$ & $\begin{array}{c}5.05 \\
(1.80)\end{array}$ \\
\hline
\end{tabular}

Both groups of participants showed significant knowledge gains. They answered significantly more questions correct in the knowledge test after watching the videos than in the test before watching the videos. A paired sample t-test to compare the pre- and post-test results of the group who watched the videos without any reference to errors ('error free') showed significant differences on the number of correctly answered questions about the explanation of the functions $(t(19)=$ $9.69, \mathrm{p}<0.001)$ and on the questions about the ability to recall the appearance of the buttons $(\mathrm{t}(19)=3.38, \mathrm{p}=$ 0.003 ). A paired sample t-test to compare the pre- and post-test results of the group who watched the videos with references to potential errors ('error guided') showed the same results: $\mathrm{t}(19)=7.49, \mathrm{p}<0.001$ (explanation of functions); $\mathrm{t}(19)=5.58, \mathrm{p}<0.001$ (recall of buttons).

No statistical differences were found between the two groups of participants. T-tests showed that there were no significant differences between number of correctly answered questions in the post-test: $\mathrm{t}(38)=1.09, \mathrm{p}=0.29$ (explanation of functions); $\mathrm{t}(38)=-.02, \mathrm{p}=0.31$ (recall buttons).

\section{Task effectiveness}

Task effectiveness was measured by observing the number of correctly performed sub-tasks (see table 2). For almost all sub-tasks, more participants in the "error guided' group performed the task correctly than participants in the 'error free' group. Chi-square tests were performed to test if the differences were statistically significant. The results showed a significant difference for two tasks: the use of capitals (Chi square $=5.71, \mathrm{p}=0.05$ ) and the use of an exclamation mark (Chi square $=7.62, \mathrm{p}$ $=0.01$ ).

TABLE 2. THE EFFECT OF THE TWO VERSIONS OF THE VIDEO INSTRUCTIONS ON THE NUMBER OF CORRECTLY PERFORMED SUB-TASKS (STATISTICALLY SIGNIFICANT DIFFERENCES IN BOLD).

\begin{tabular}{|l|c|c|}
\hline & $\begin{array}{l}\text { Video without } \\
\text { reference to } \\
\text { errors }\end{array}$ & $\begin{array}{l}\text { Video in which } \\
\text { errors were } \\
\text { addressed }\end{array}$ \\
\hline Dub-tasks & 2 & 6 \\
\hline Backssis & 17 & 20 \\
\hline Capital & $\mathbf{1 5}$ & $\mathbf{2 0}$ \\
\hline Caps Lock & 14 & 18 \\
\hline $\begin{array}{l}\text { Exclamation } \\
\text { mark }\end{array}$ & $\mathbf{1 0}$ & $\mathbf{1 8}$ \\
\hline Smiley face & 20 & 20 \\
\hline ABS Key & 18 & 19 \\
\hline Blue button & 19 & 20 \\
\hline
\end{tabular}

\section{Satisfaction and self-efficacy}

Two weeks after task performance, participants were asked about their satisfaction with the instructions and their self-efficacy level. Not all participants were able to answer these follow-up questions. Thirty four participants answered the question whether they were satisfied with the instruction session. Sixteen of them watched the instructions without references to errors and 18 of them had watched instructions with references to potential errors. A large majority of the participants (31) indicated that they were satisfied with the video instructions. One of them told us: "Very nice! I practiced several times. I can 
find all kind of things on YouTube; that's fun!" And another participant said: "Fantastic! I send e-mails every day." Others were satisfied, but a bit less enthusiastic: "Hard to remember all things, but it was nice. I manage quite well." No differences were found between the two groups of participants with regard to their level of satisfaction.

During the interview, participants frequently mentioned themselves that they had been practising over the last two weeks. If they did not spontaneously mention this topic, they were asked about it. Fourteen out of eighteen participants in the 'error guided' group compared to six out of sixteen participants in the "error free' group, said that they had been practicing: "I practice every day", "Yes, very nice ... back and forth with my sister". Participants who watched videos in which potential errors were addressed seemed to be more encouraged to practices sending e-mails afterwards or to explore the functions of the tablet computer.

Furthermore, participants who watched the videos with references to errors seemed to have gained more confidence than the participants in the other group. In the interview, 26 participants responded to a question about how confident they were about their skills to use the tablet computer. Two out of 11 participants who watched videos without references to errors answered that they gained confidence, against 10 out of 18 participants who watched videos with references to potential errors. The focus on potential errors and how to repair them, seems to have positive effects on the participants' level of self-efficacy.

\section{CONCLUSIONS}

As most studies, the current study has some limitations. The most important limitation is that the experimental procedure was not exactly the same for every participant. The tasks were very challenging and some participants needed more guidance than others. In case they needed more guidance than was offered in the instructional videos, the researcher or a family member who was present offered help. This may have distorted the results a little bit. Furthermore, in selecting participants for this study, potential participants were not asked if they were interested in learning how to send e-mail messages using the Compaan tablet computer. During the study, it became clear there was no need for some participants to learn to send e-mails, because they do not have (enough) e-mail contacts. This may have affected the motivation level of these participants. Although the tasks were challenging for this target group and although the task of sending e-mail messages was not relevant for all participants, most participants were interested and motivated to learn to use the tablet.

Despite the limitations, the results of this study - one of the few studies in which people over 75 years of age participated - are valuable. The first conclusion of this study is that it is possible to teach seniors over 75 years old basic computer skills by using instructions that consider the specific needs of this age group. These results confirm other studies' assumptions [15] - [17].

The goal of this study was to compare the effects of error guided instructional video materials with the effects of instructional video materials that did not include information on potential errors. It was expected that including information on how to recognize errors and how to repair them would have positive effects on learning progress, task performance and satisfaction and selfefficacy levels, in line with the Minimalist approach to instructional design [21]. However, including information on potential errors also results in more extended instructional materials, which may have adverse effects. The results show moderate differences between the two groups of participants, in favour of the instructions that included information on potential errors. Participants who watched 'error guided' video instructions performed more tasks correctly and, more important, they seemed to be more motivated to practice what they have learned. Therefore, focusing on potential errors is important. This helps people to keep using the technology, probably because they are less afraid to make errors.

We hope that the results of this study contribute to a higher level of technology adoption among seniors. This can be beneficial in dealing with ageing problems as health, mobility and social isolation.

\section{ACKNOWLEDGEMENTS}

We would like to thank Joost Hermanns (Compaan Company) for the opportunity to use the Compaan tablet.

\section{REFERENCES}

[1] R. Beacker et al., "Technology to reduce social isolation and loneliness." in Proc. ACM SIGACCESS Conf. on Comput. \& Accessibility (ASSETS '14). 2014, pp. 27-34.

[2] T. L. Mitzner et al., "Older adults' training preferences for learning to use technology."in Proc. Human Factors and Ergonomics Soc. Annual Meeting. 2008, pp. 2047-2051.

[3] B. Y. M. Anderson and A. Perrin, "Tech adoption climbs among older adults,". [Online] Available: http://www.pewinternet.org/2017/05/17/technology-use-amongseniors/

[4] T. L. Mitzner et al., "Predicting older adults' perceptions about a computer system designed for seniors," Universal Access Inform. Soc., vol. 15, no. 2, pp. 271-280, 2016.

[5] N. R. Loorbach, Motivational Elements in User Instructions. $\mathrm{PhD}$. Dissertation, University Twente, 2013.

[6] H. Wandke, et al., "Myths about older people's use of information and communication technology," Gerontology, vol. 58, no. 6, pp. 564-570, 2012. 
[7] M. Ziefle et al., "How younger and older adults master the usage of hyperlinks in small screen devices." in Proc. SIGCHI Conf. on Human Factors in Computing Syst. (CHI 2007). 2007, pp. 307-316.

[8] A. E. Pohlmeyer et al., "The value of answers without question [s]: A qualitative approach to user experience and aging." In Proc. Int. Conf. on Human Centered Design. 2009, pp. 894-903.

[9] M. Karavidas et al., "The effect of computers on older adult users," Comput. In Human Behavior, vol. 21, no.5, pp. 697-711.

[10] M. J. Sanders et al., "Computer Training for Seniors: An Academic-Community Partnership," Edu. Gerontology, vol. 39, no. 3, pp. 179-193, 2013.

[11] P. W. M. Van Gerven et al., "Cognitive aging and computer-based instructional design: Where do we go from here?," Edu. Psychol. Rev., vol. 18, no. 2, pp. 141-157, 2006.

[12] E. D. Freeman et al., "Improving website accessibility for people with early-stage dementia: a preliminary investigation," Aging \& Mental Health, vol. 9, no. 5, pp. 442-448, 2005.

[13] P. Vermaas et al., A Philosophy of Technology - From Technical Artefacts to Sociotechnical Systems. Morgan \& Claypool, 2011.

[14] H. J. Schuiteman, The Use of ICT to Support Informal Caregiving in Eldercare: A Systemic Approach. MSc. Thesis, Wageningen University \& Research, 2016.

[15] S. J. Czaja and C. C. Lee, "The impact of aging on access to technology,". Universal Access in the Inform. Soc., vol. 5, no. 4, pp. 341-349, 2007.

[16] B. B. Neves et al., "My hand doesn't listen to me!": Adoption and evaluation of a communication technology for the "oldest old."," in Proc. ACM CHI'15 Conf. Human Factors Comput. Syst. 2015, pp. 1593-1602.

[17] C. B. Mayhorn et al., "Older adults, computer training, and the systems approach: a formula for success," Edu. Gerontology, vol. 30, no. 3, pp. 185-203, 2004.

[18] C. Bruderet al., "Training the elderly in the use of electronic devices BT - Universal access in human computer interaction: Coping with diversity," in Proc. UAHCI, HCI International. 2007, pp. 637-646.

[19] D. Gramss and D. Struve, "Instructional videos for supporting older adults who use interactive systems," $E d u$. Gerontology, vol. 35, no. 2, pp. 164-176, 2009.
[20] D. Struve and H. Wandke, "Video modeling for training older adults to use new technologies," ACM Trans. Access. Comput ., vol. 2, no. 1, 2009.

[21] H. van der Meij and J. M. Carroll, "Principles and heuristics for designing minimalist instruction," in Minimalism Beyond the Nurnberg Funnel, J. M. Carroll, Ed. MA: Mit Press, 1998, pp. 19-53.

[22] M. Gellevij and H. van der Meij, "Empirical proof for presenting screen captures in software documentation," Tech. Commun., vol. 51, no. 2, pp. 224-238, 2004.

[23] H. van der Meij and J. van der Meij, "Eight Guidelines for the Design of Instructional Videos for Software Training," Tech. Commun., vol. 60, no. 3, pp. 205-228, 2013.

[24] N. Loorbach, et al., "Adding motivational elements to an instruction manual for seniors: Effects on usability and motivation," Tech. Commun., vol. 54, no. 3, pp. 343-358, 2007.

[25] R. E. Mayer, "Using multimedia for e-learning," J. Comp. Assisted Learning, vol. 33, pp. 403-423, 2017.

[26] J. Swarts, "New Modes of Help: Best Practices for Instructional Video," Tech. Commun., vol. 59, no. 3, pp. 195206, 2012.

\section{ABOUT THE AUTHORS}

Marianne Scheepens is the owner of a graphic design company (Mans57). She received an MSc degree in Communication Studies from the University of Twente, Enschede, the Netherlands in 2017. She is interested in supporting elderly people to make optimal use of technology.

Joyce Karreman is an assistant professor of Technical Communication at the University of Twente, Enschede, the Netherlands. Her research interests include the design of instructive documents, human-centered design processes and intercultural issues related to usability and user experience. She has presented her work at international conferences and has published in several journals.

Menno de Jong is a full professor of Communication Science at the University of Twente, Enschede, the Netherlands. He has published articles on corporate communication, document design, and on various methods of usability evaluation. He edited Technical Communication between 2009 and 2015. 